\title{
Aqueous alteration in the Northwest Africa 817 (NWA 817) Martian meteorite
}

\author{
Ph. Gillet ${ }^{\mathrm{a}, *}$, J.A. Barrat ${ }^{\mathrm{b}}$, E. Deloule ${ }^{\mathrm{c}}$, M. Wadhwa ${ }^{\mathrm{d}}$, A. Jambon ${ }^{\mathrm{e}}$,

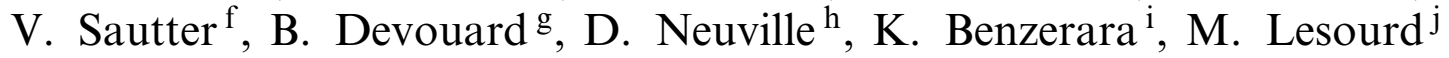 \\ a Laboratoire des Sciences de la Terre (UMR CNRS 5570), Ecole Normale Supérieure de Lyon, 46 allée d'Italie, 69346 Lyon, France \\ b Laboratoire de Géodynamique et Planétologie (UMR CNRS 6112) and Université d'Angers, 2 boulevard Lavoisier, \\ 49045 Angers Cedex, France \\ c Centre de Recherches Pétrologiques et Géochimiques (UPR CNRS 2300), P.O. Box 20, 54501 Vandoeuvre les Nancy Cedex, France \\ d Department of Geology, The Field Museum, Chicago, IL 60605, USA \\ e Laboratoire MAGIE, Université de Paris VI, Paris, France \\ f Laboratoire de Minéralogie, Muséum National d'Histoire Naturelle, Paris, France \\ g Laboratoire Magmas et Volcans (UMR CNRS 6524), Université Blaise Pascal, Clermont Ferrand, France \\ h Département des Géomatériaux, ESA CNRS 7046, IPG Paris, 4 place Jussieu, 75252 Paris, France \\ i Laboratoire de Minéralogie et Cristallographie, Université de Paris VI, Paris, France \\ j CNRS et SCIAM, Laboratoire d'Histologie, UFR de Médecine, Université d'Angers, 1 rue Haute de Reculée, 49045 Angers Cedex, \\ France
}

Received 4 April 2002; accepted 11 July 2002

\begin{abstract}
Samples of a new Martian meteorite of the nakhlite family (NWA 817) contain traces of an iron-rich alteration product. Textural arguments indicate that this alteration product has been formed on the parent body of the meteorite (Mars). The chemical composition and structural data (X-ray diffraction, transmission electron microscopy and vibrational spectroscopy) show that the alteration mineral is a hydrous phase from the smectite family. Major elements and rare earth elements suggest that the formation of the alteration phase is related to the circulation of an aqueous fluid which composition is controlled by the dissolution of feldspars to account for a positive Eu anomaly, olivine and possibly apatite. Hydrogen isotope data display negative $\delta \mathrm{D}$ values ranging from -60 to $-280 \%$ in olivine and pyroxenes and from -140 to $-181 \%$ in the alteration phase. The values of $\delta \mathrm{D}$ for the alteration product show a small scatter with a mean value of $-170 \pm 14 \%$. These values are lower than those previously obtained on other Martian meteorites, which give mainly positive $\delta \mathrm{D}$ values. These positive values have been interpreted as resulting from the interaction of the Martian meteorites with water from the Martian atmosphere. Ruling out the effect of terrestrial alteration, it is suggested that alteration in the NWA 817 meteorite was likely produced on Mars by the circulation of an aqueous fluid originating from a chemical reservoir, such as the Martian mantle, which has not equilibrated with a fractionated Martian atmosphere.
\end{abstract}

(C) 2002 Elsevier Science B.V. All rights reserved.

Keywords: Martian meteorites; nakhlite; alteration; D/H; geochemistry

\footnotetext{
* Corresponding author. E-mail address: philippe.gillet@ens-lyon.fr (P. Gillet).
} 


\section{Introduction}

The presence in the past of large quantities of water on the surface of Mars has been inferred from the study of valley networks and other morphological features. The identification and characterization of water reservoirs (internal and external) on Mars can also be done indirectly through petrographic and chemical studies of pre-terrestrial alteration products in the SNC meteorites which are thought to be pieces of Mars delivered to the Earth's surface [1]. Several such studies have been performed so far on the three known meteorites of the nakhlite subclass (Nakhla, Lafayette and Governador Valadares). These meteorites represent shallow crustal rocks showing clear evidence of pre-terrestrial low-temperature aqueous alteration [2-5]. The predominant alteration products of these meteorites are: a material loosely termed iddingsite that fills fractures crosscutting magmatic minerals and mesostasis, siderite and evaporitic minerals including halite, gypsum and anhydrite. Hydrogen isotope systematics indicate that these rocks have been altered by a fluid that equilibrated with the fractionated Martian atmosphere [6]. A fourth nakhlite, Northwest Africa 817 (NWA 817), has recently been discovered in the Sahara [7].

The present study provides the description and interpretation of the alteration products observed in this meteorite. They have been characterized with the following analytical techniques: optical microscopy, scanning electron microscopy (SEM), electron microprobe, secondary ion mass spectrometry (SIMS), high-resolution transmission electron microscopy (TEM), X-ray diffraction, IR and Raman spectroscopy (see Appendix for the description of these techniques).

\section{NWA 817: a Martian meteorite}

NWA 817 is a $104 \mathrm{~g}$ stone found in the Moroccan desert. The mineralogy consists of euhedral subcalcic augite (Wo38-40, En38-27, Fs24-34) olivine (extensively zoned from Fa-57 in the core to Fa-86 in the rim) with crystallized magmatic inclusions and a multi-component mesostasis composed of fine-grained feldspars, acicular pyroxenes, a silica phase (cristobalite), minute amounts of sulfide droplets, and Ti-magnetite in a glassy matrix [7]. NWA 817, like the three other known nakhlites, shows no obvious shock features like melt pockets, high-pressure minerals or planar deformation features [8]. The NWA 817 meteorite is an unbrecciated, olivine-bearing clinopyroxenite with a cumulate texture $[7,8]$. Modal analyses indicate the following mineral proportions: $69 \mathrm{vol} \%$ pyroxene, $15 \%$ olivine, $15 \%$ mesostasis and $1 \% \mathrm{Fe}-\mathrm{Ti}$ oxides. Key element ratios such as $\mathrm{FeO} / \mathrm{MnO}(=37), \mathrm{Na} / \mathrm{Al}(=0.40), \mathrm{K} /$ $\mathrm{La}(=449), \mathrm{Ga} / \mathrm{La}\left(=3.9 \times 10^{-4}\right)$ and oxygen isotopic composition $\left(\Delta^{17} \mathrm{O}=+0.37 \%\right.$ o $)$ are clear evidence for including this meteorite in the SNC group [7]. Rare gas studies also indicate a martian origin for this meteorite [9].

\section{The alteration products: textural observations}

Alteration in NWA 817 is readily apparent in hand samples and in thin sections as reddish patches or veins (Fig. 1A). The reddish alteration product is clearly post-magmatic as it often crosscut olivines, the mesostasis and, more rarely, pyroxenes. In the mesostasis it occurs as patches rather than as well-defined veinlets (Fig. 1B). In olivines, it occurs mostly as veinlets with, in some cases, irregular and saw-tooth margins very similar to those described in the Lafayette meteorite [3,4] (Fig. 1C). The veinlets appear to be mostly homogeneous, with the exception of some compositional zoning mostly near their margins (Fig. 1D). These zoning features as well as the texture suggest that the veins may be hydrothermal in origin, with multiple episodes of deposition of material. Unlike the 'iddingsite-like' alteration materials reported from Nakhla and Lafayette [2], optical and SEM observations show no evidence for the presence of a complex polycrystalline and polymineralic mixture in this alteration product. No siderite or other carbonates were observed in association with the orange material.

The extraterrestrial origin of this alteration can only be demonstrated indirectly since we were not able to observe relationships between the fusion 
crust and the alteration veinlets in the samples we have used for making thin sections and polished sections. However, other arguments strongly suggest that the orange material was formed during pre-terrestrial alteration of the meteorite. A general inspection of the main mass of the meteorite using a binocular microscope did not reveal orange veinlets crosscutting the fusion crust or orange weathering products at the surface of the fusion crust. The alteration product occurs in textural settings similar to those observed for the pre-terrestrial 'iddingsite-like' material in the three other nakhlites. Finally, textural evidence indicates that NWA 817 underwent only very minimal, if any, alteration in the terrestrial environment, thereby also lending support to a preterrestrial origin of the alteration of the magmatic minerals. Most meteorites recovered from the Saharan desert have suffered different degrees of alteration. We have studied several of these meteorites, including three new shergottites [10-12]. Typically, terrestrial alteration is marked by the deposition of calcite from terrestrial fluids circulating in the cracks and fractures in these rocks. Such calcite, however, is present in very minor amounts in NWA 817. Additionally, the rare occurrences of sulfides (which are known to be highly susceptible to terrestrial alteration) in NWA 817 appear to be very fresh. Finally, even the most altered olivine and pyroxenes of Saharan meteorites never display such alteration textures. Trace element composition of the alteration product provides further evidence for a pre-terrestrial formation (see Section 4).

\section{The alteration product: structural data}

A typical X-ray spectrum of an olivine containing the orange alteration product is shown in Fig. 2A. Besides the strong olivine diffraction peaks, additional peaks occur between 9 and $1.2 \mathrm{~nm}$, with some peaks occurring between 1.4 and 1.5 $\mathrm{nm}$. These peaks are in agreement with the $d$ spacings of phyllosilicates of the smectite family. High-resolution TEM data reveal a poorly crystallized material with lattice fringes varying between 0.9 and $1.1 \mathrm{~nm}$ (Fig. 2B), in agreement with the X-ray data. Additional spectroscopic data further confirm the mineralogical nature of the alteration phase. Raman spectra exhibit broad peaks at low wavenumbers $\left(216 \mathrm{~cm}^{-1}, 278 \mathrm{~cm}^{-1}\right.$, $598 \mathrm{~cm}^{-1}$ and $760 \mathrm{~cm}^{-1}$ ), confirming its ill-organized nature (Fig. 2C). The spectrum bears strong similarities with those of smectites and kaolinites [13]. Infrared spectra show a very intense and large absorption band near $3600 \mathrm{~cm}^{-1}$, suggestive of the presence of $\mathrm{OH}$ or $\mathrm{H}_{2} \mathrm{O}$ molecules (Fig. 2D).

\section{The alteration product: chemical characterization}

The major element composition of the alteration phase occurring in olivines and in the mesostasis is given in Table 1 and Fig. 3A. Fig. 3A shows that the composition does not overlap with the compositional fields defined by the major minerals. The low analytical totals $(86-88 \mathrm{wt} \%)$ and the absence of significant amounts of $\mathrm{Cl}, \mathrm{F}$ and $\mathrm{C}$ suggest the presence of water, which is consistent with the infrared data. The major element composition, which is dominated by $\mathrm{Si}, \mathrm{Mg}$ and $\mathrm{Fe}$, resembles that of a ferromagnesian smectite. In the absence of a more detailed crystal chemical study, including a structure refinement, it is for the moment difficult to provide a structural formula for the alteration phase and a detailed interlayer cation content of this smectitelike mineral.

The alteration phase (in olivines as well as in the mesostasis) is enriched in $\mathrm{Fe}$ relative to the olivines (Fig. 3A). In particular, it should be noted that the $\mathrm{Fe} / \mathrm{Mg}$ ratio of the alteration phase is not controlled by the composition of the adjacent olivines (Fig. 3B). There is a clear correlation between $\mathrm{Si}$ and $\mathrm{Fe}$ contents of the alteration phase. However, in the plot of $\mathrm{FeO} / \mathrm{MgO}$ vs. $\mathrm{SiO}_{2} / \mathrm{MgO}$, the compositions of the alteration phase in the mesostasis and in the olivine define distinct trends (Fig. 3A). This trend cannot be explained in the absence of a more comprehensive crystal chemical characterization of this clay mineral. The plot of $\mathrm{CaO} / \mathrm{MgO}$ vs. $\mathrm{SiO}_{2} / \mathrm{MgO}$ indicates that most of the $\mathrm{Ca}$ in the alteration phase is 

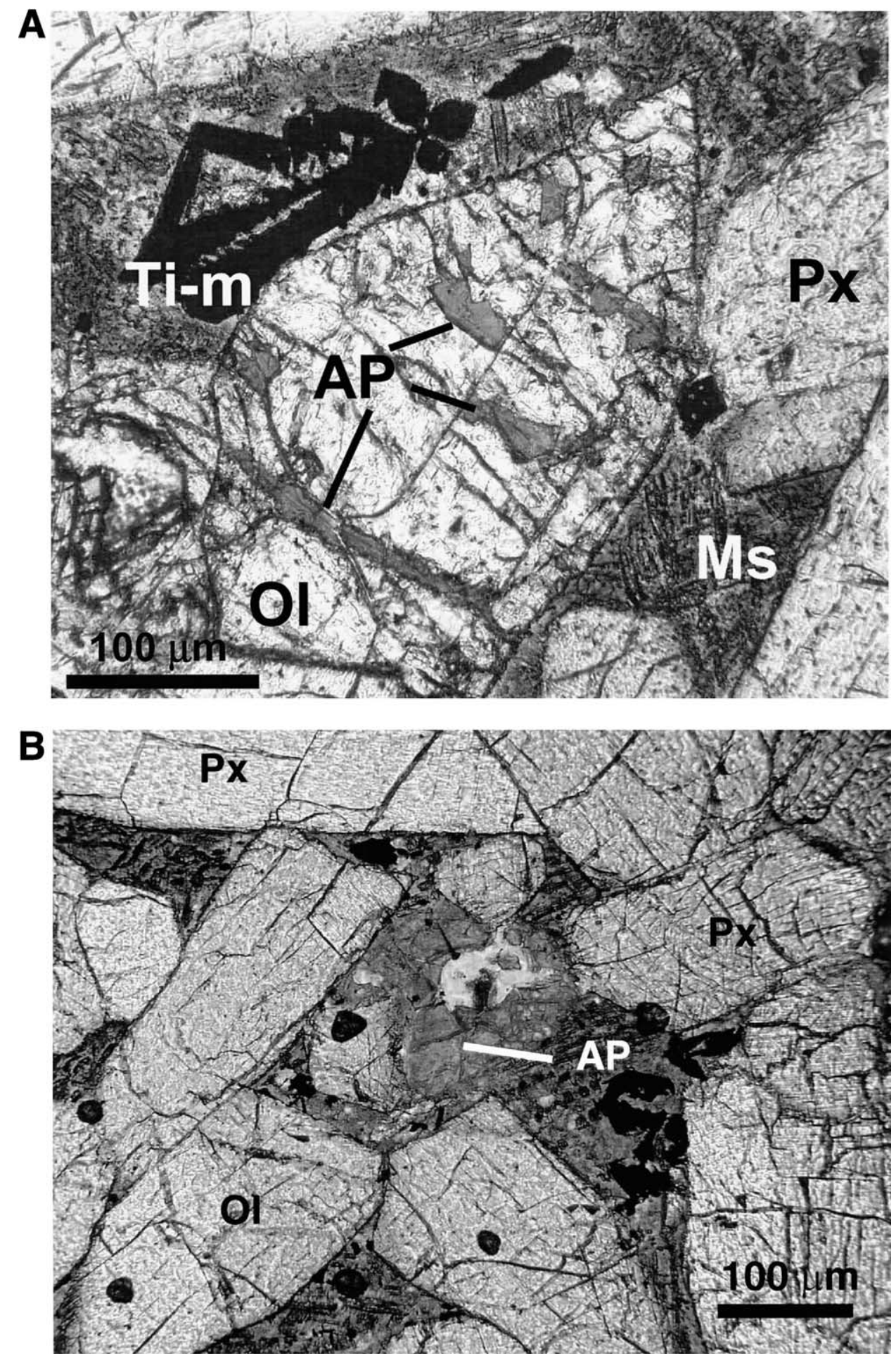

Fig. 1. 

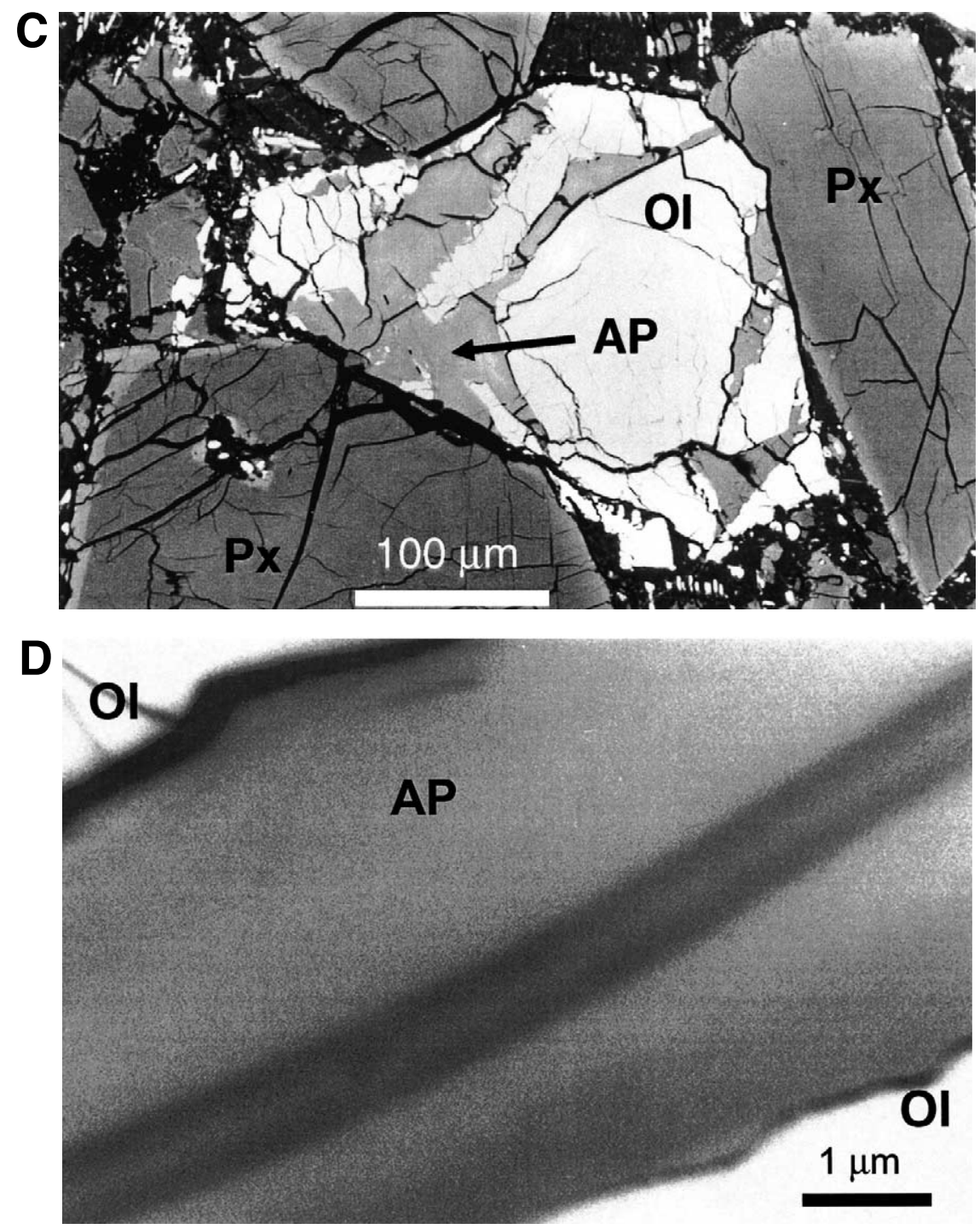

Fig. 1 (Continued). Microphotographs of the alteration product in NWA 817. (A) and (B) are optical photographs taken under polarized light. (A) The alteration product forming veinlets in an olivine crystal. (B) A patch of alteration product in the mesostasis. (C) Backscattered electron image of veinlets of alteration phase in an olivine crystal. Notice the saw-tooth margin forms of some veinlets. (D) High resolution backscattered electron image of the alteration product. Darker veins are regions less-rich in $\mathrm{Fe}$. $\mathrm{AP}=$ alteration product $; \mathrm{Px}=$ pyroxene $; \mathrm{Ol}=$ olivine $; \mathrm{Ms}=$ mesostasis $; \mathrm{Ti}-\mathrm{m}=$ titano-magnetite .

not derived from the high-Ca phases (i.e. the pyroxenes or the mesostasis) (Fig. $3 \mathrm{~A})$. Al is abundant in the alteration phase in the mesostasis $\left(\mathrm{Al}_{2} \mathrm{O}_{3}\right.$ up to $\left.\sim 4 \mathrm{wt}^{\%} \%\right)$ but is only present in minor amounts $\left(<1 \mathrm{wt} \% \mathrm{Al}_{2} \mathrm{O}_{3}\right)$ when located in the olivines (Table 1). These data indicate that the smectite-related phase formed in an open system by the circulation of an aqueous fluid that transported elements such as $\mathrm{Si}, \mathrm{Mg}, \mathrm{Fe}$ and $\mathrm{Ca}$ into the rock. Nevertheless, the distinct compositional trends observed when located in the mesostasis or in the olivines suggest that minor amounts of some of these elements (particularly, $\mathrm{Si}$ and $\mathrm{Fe}$ ) were contributed by these phases. Finally, the distribution of some of the less abundant elements, such as Al, may be largely con- 

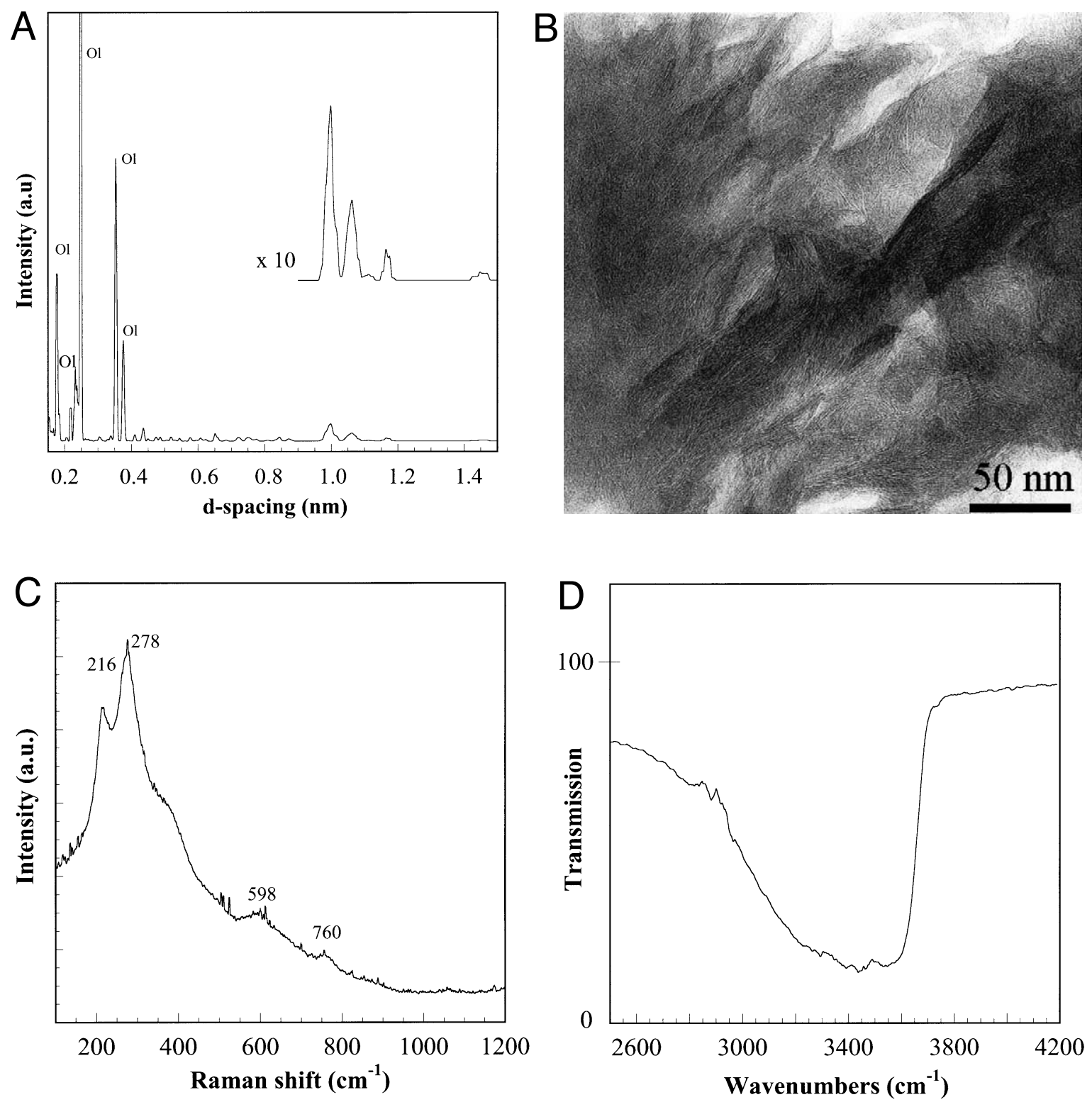

Fig. 2. Structural data on the alteration product in NWA 817. (A) X-ray pattern obtained on a single crystal of olivine containing the alteration phase. The strong diffraction lines below $0.6 \mathrm{~nm}$ correspond to olivine. Weak broad peaks are observed between 0.9 and $1.2 \mathrm{~nm}$ compatible with diffraction planes of phyllosilicates of the smectite family. (B) High-resolution transmission electron photomicrograph of alteration phase. The image shows an ill-organized crystal with different lattice spacings between 0.9 and $1.1 \mathrm{~nm}$, in agreement with the X-ray data. (C) Raman spectrum obtained on the alteration phase. The spectrum is close to that of a smectite. The broad bands at $216 \mathrm{~cm}^{-1}, 278 \mathrm{~cm}^{-1}, 598 \mathrm{~cm}^{-1}$ and $760 \mathrm{~cm}^{-1}$ are characteristic of a poorly crystalline material. (D) Infrared spectrum of the alteration phase. The broad band near $3600 \mathrm{~cm}^{-1}$ corresponds to absorption by OH or $\mathrm{H}_{2} \mathrm{O}$ molecules in the mineral. 
Table 1

Major element composition of the alteration products in NWA 817 and other nakhlites (in $\mathrm{wt}^{\%} \%$ )

\begin{tabular}{|c|c|c|c|c|c|c|c|c|c|c|c|}
\hline & $\mathrm{SiO}_{2}$ & $\mathrm{TiO}_{2}$ & $\mathrm{Al}_{2} \mathrm{O}_{3}$ & $\mathrm{Cr}_{2} \mathrm{O}_{3}$ & $\mathrm{FeO}$ & $\mathrm{MnO}$ & $\mathrm{MgO}$ & $\mathrm{CaO}$ & $\mathrm{Na}_{2} \mathrm{O}$ & $\mathrm{K}_{2} \mathrm{O}$ & Total \\
\hline \multicolumn{12}{|c|}{ NWA 817 - alteration products in the mesostasis } \\
\hline \#1 & 47.35 & 0.01 & 2.46 & 0.00 & 27.15 & 0.23 & 8.66 & 0.18 & 0.06 & 0.47 & 86.57 \\
\hline \#2 & 45.01 & 0.09 & 3.09 & 0.00 & 30.56 & 0.36 & 5.92 & 0.16 & 0.03 & 0.42 & 85.64 \\
\hline Average, $n=16$ & 46.51 & 0.03 & 2.26 & 0.01 & 28.42 & 0.28 & 7.56 & 0.14 & 0.06 & 0.42 & 85.68 \\
\hline \multicolumn{12}{|c|}{ NWA 817 - alteration products in olivine crystals } \\
\hline \#3 & 43.31 & 0.06 & 0.17 & 0.00 & 35.87 & 0.43 & 6.40 & 0.19 & 0.13 & 0.47 & 87.03 \\
\hline \#4 & 42.82 & 0.04 & 0.05 & 0.02 & 37.34 & 0.58 & 5.10 & 0.12 & 0.21 & 0.45 & 86.72 \\
\hline Average, $n=25$ & 42.82 & 0.06 & 0.21 & 0.03 & 36.45 & 0.55 & 5.69 & 0.25 & 0.18 & 0.41 & 86.65 \\
\hline \multicolumn{12}{|l|}{ Nakhla 'rust' [3] } \\
\hline & 40.20 & 0.02 & 0.74 & 0.03 & 34.10 & 0.63 & 6.82 & 1.14 & 1.16 & 0.60 & 85.44 \\
\hline \multicolumn{12}{|c|}{ Lafayette iddingsite (total arbitrary fixed to $86 \%$ ) [4] } \\
\hline & 42.79 & 0.01 & 4.16 & 0.00 & 25.28 & 0.42 & 12.11 & 0.61 & 0.26 & 0.36 & 86.00 \\
\hline
\end{tabular}

trolled by contributions from the minerals in which the alteration phase was deposited.

Trace element abundances in alteration products can provide constraints on the origin of fluids responsible for their formation [5,14]. Table 2 and Fig. 3C give the range of rare earth element (REE) concentrations measured in the orange phase located in olivine by in situ ion microprobe analyses $[15,16]$. The alteration phase is characterized by a striking V-shaped REE pattern with a marked positive Eu anomaly (Fig. 3B). REE abundances in Saharan meteorites can be strongly modified by surface processes $[12,17,18]$. Therefore, the effects of terrestrial weathering need to be evaluated. It has previously been noted that the REE patterns of terrestrially weathered minerals usually show light-REE (LREE) enrichment, and often have a positive or negative Ce anomaly. Unlike the Libyan shergottites from the Dar al Gani area, NWA 817 is a relatively fresh rock and contains only very minor amounts of desert alteration products (such as calcite), mostly located near the surface or in some fractures. Magmatic phases, with the exception of olivine, do not show LREE enrichment [19]. Olivine has the lowest REE abundances of all the magmatic phases and is thus extremely sensitive to the addition of even small amounts of LREE during terrestrial weathering. Therefore, only very small amounts of LREE are likely to have been added by terrestrial contamination, which resulted in moderate enrichment of these elements in the olivine (La $\sim 0.5 \times \mathrm{CI}$ ) but cannot account for the extreme
LREE enrichment in the alteration phase (La $\sim 6-8 \times \mathrm{CI}$ ). Furthermore, the LREE enrichment in the alteration phase is positively correlated with the size of the Eu anomaly (Fig. 3D). Saharan weathering processes are unlikely to have resulted in such a relationship. Finally, no Ce anomaly has been found in the REE patterns of the alteration phase (Fig. 3C). Therefore, the REE abundances in the alteration product are unlikely to have been the result of terrestrial weathering. Additional work, including analyses of light elements $(\mathrm{Li}$, $\mathrm{Be}, \mathrm{B} . .$.$) should further confirm this result.$

Table 2

Range of REE abundances (in ppm) in the alteration phase. AP 3-3.4 is the average of two analyses from the same area

\begin{tabular}{lll}
\hline & AP $2-2$ & AP $3-3.4$ \\
\hline $\mathrm{Y}$ & $1.81 \pm 4$ & $3.17 \pm 5$ \\
$\mathrm{La}$ & $1.46 \pm 5$ & $1.94 \pm 5$ \\
$\mathrm{Ce}$ & $2.60 \pm 7$ & $4.11 \pm 8$ \\
$\mathrm{Pr}$ & $0.32 \pm 2$ & $0.48 \pm 2$ \\
$\mathrm{Nd}$ & $0.95 \pm 3$ & $1.78 \pm 4$ \\
$\mathrm{Sm}$ & $0.15 \pm 1$ & $0.41 \pm 2$ \\
$\mathrm{Eu}$ & $0.20 \pm 2$ & $0.17 \pm 4$ \\
$\mathrm{Gd}$ & $0.08 \pm 3$ & $0.18 \pm 4$ \\
$\mathrm{~Tb}$ & $0.019 \pm 5$ & $0.054 \pm 6$ \\
$\mathrm{Dy}$ & $0.17 \pm 1$ & $0.41 \pm 2$ \\
$\mathrm{Ho}$ & $0.051 \pm 5$ & $0.115 \pm 8$ \\
$\mathrm{Er}$ & $0.21 \pm 1$ & $0.46 \pm 2$ \\
$\mathrm{Tm}$ & $0.036 \pm 4$ & $0.090 \pm 6$ \\
$\mathrm{Yb}$ & $0.32 \pm 2$ & $0.74 \pm 3$ \\
$\mathrm{Lu}$ & $0.067 \pm 6$ & $0.152 \pm 9$ \\
$(\mathrm{La} / \mathrm{Sm})_{\mathrm{n}}$ & 6.20 & 2.95 \\
$(\mathrm{Dy} / \mathrm{Yb})_{\mathrm{n}}$ & 0.36 & 0.36 \\
$(\mathrm{Eu} / \mathrm{Sm})_{\mathrm{n}}$ & 3.54 & 1.09 \\
\hline
\end{tabular}


The heavy-REE (HREE) pattern in the alteration phase is similar to that in olivine (chondritenormalized $\mathrm{Yb} / \mathrm{Dy} \sim 3$ ) although average concentrations are somewhat higher in the alteration phase ( $\mathrm{Yb} \sim 2-5 \times \mathrm{CI}$ versus $\sim 0.7-1.1 \times \mathrm{CI}$ in olivine). As noted earlier, the degree of LREE enrichment in the alteration phase is variable (chondrite-normalized $\mathrm{La} / \mathrm{Sm} \sim 3-6$ ) and correlates with the size of the Eu anomaly (chondrite-normalized Eu/Sm 1.0-3.5) (Fig. 3C). These REE distributions could be explained assuming that the fluids that deposited the alteration product percolated through a nakhlitic sequence and dissolved various magmatic phases to different degrees. Dissolution of olivine, which has a steep HREE-enriched pattern, is likely to be the major source of the HREE; this would explain the similarity of the HREE pattern of the olivine and the alteration product. The dissolution of two other minerals, rich in REE and present in the nakhlites, must be involved to explain the LREE patterns and $\mathrm{Eu}$ anomalies in the alteration product. Chlorapatite, which is the principal carrier of REE in the nakhlites, and plagioclase both have LREE-enriched patterns (chondrite-normalized $\mathrm{La} / \mathrm{Sm} \sim 3$ and $\sim 6$, respectively). Dissolution of plagioclase is required to explain the positive Eu anomaly observed in the alteration product. Therefore, variable contributions from these two minerals can account for the range of LREE enrichments and the sizes of $\mathrm{Eu}$ anomalies in the alteration phase. It is worth noting that on Earth, hydrothermal fluids in mid-oceanic ridge basalts also have a positive $\mathrm{Eu}$ anomaly, resulting from dissolution of plagioclase in the oceanic crust by oceanic water [20]. In the absence of a more precise crystal chemical study, including a structure refinement, it is impossible to provide a structural formula for the alteration phase and a detailed interlayer cation content of this smectite-like mineral. It is also difficult to propose at the present stage a comprehensive model for the formation of the alteration phase from a fluid of yet unknown composition. Nevertheless, the chemical data presented in this study provide a general outline of the alteration process which took place in this martian magmatic rock. The composition in major elements of the alteration phase could be roughly satisfied
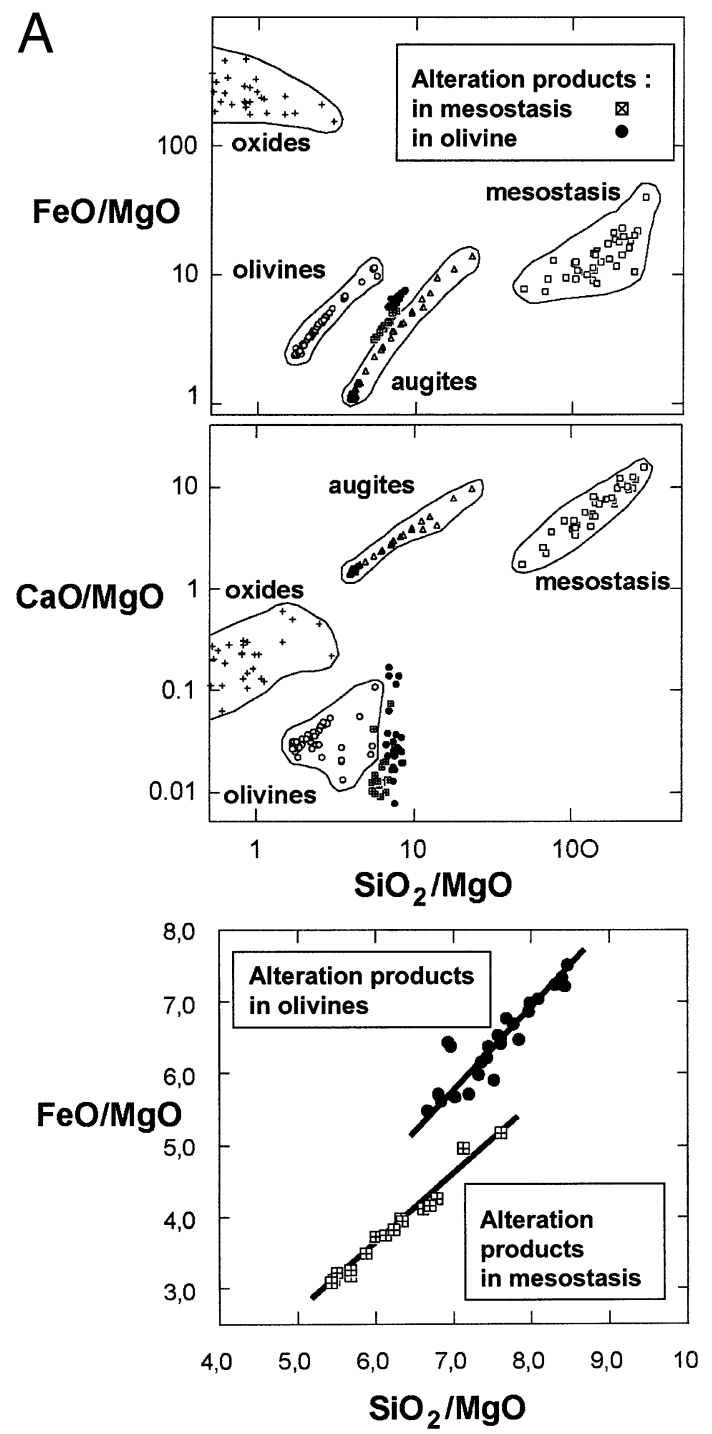

Fig. 3. (A) Comparison of the major element compositions of the alteration phase with those of the magmatic phases in NWA 817. The compositions of the alteration phase show correlations between the $\mathrm{Si}$ and $\mathrm{Fe}$ contents (uppermost and lowermost diagrams). (B) Chemical $\mathrm{Fe} / \mathrm{Mg}$ profile measured on a veinlet of the alteration phase occurring in an olivine crystal (see also Fig. 1D). (C) Comparison of the REE compositions of the alteration phase with those of the magmatic phases in NWA 817. The NWA 817 whole-rock data are from Sautter et al. [7]. REE abundances are normalized to the values of Evensen et al. [40]. (D) $(\mathrm{Eu} / \mathrm{Sm})_{\mathrm{n}}$ vs. $(\mathrm{La} / \mathrm{Sm})_{\mathrm{n}}$ in the alteration phase. Same abbreviations as in Fig. 1. 

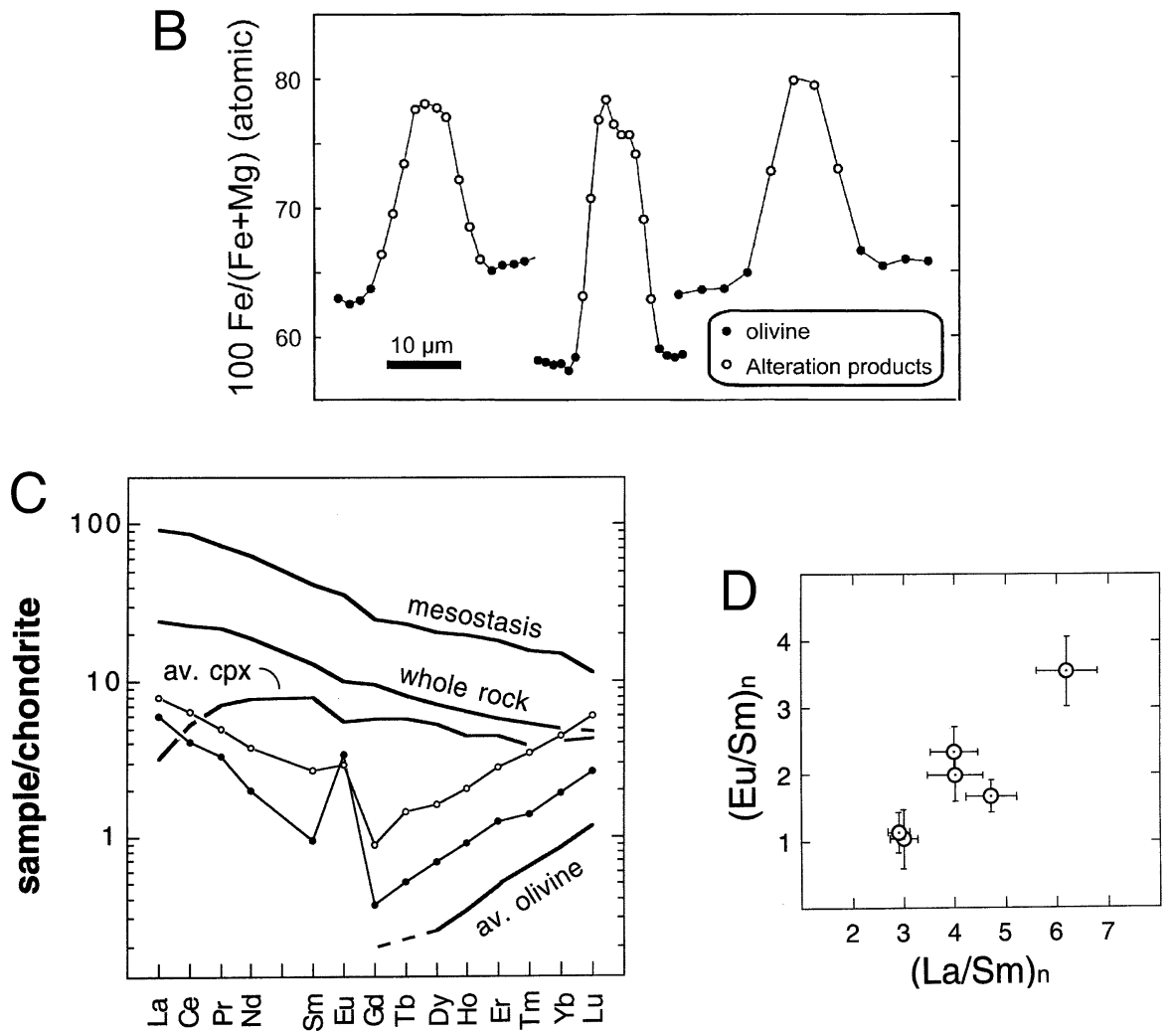

Fig. 3 (Continued).

by a mix of olivine and mesostasis [3,4]. However, the trace element composition of the alteration phase cannot be accounted for by such a simple mixture.

\section{Hydrogen isotopes in NWA 817}

Hydrogen isotope measurements have been made in situ with an ion microprobe on magmatic minerals and the alteration phase (Fig. 4) [21]. Details of the analytical procedure are given in the Appendix. The measured $\delta \mathrm{D}$ values for olivine and clinopyroxene range from -100 to $-240 \%$, and in the alteration phase from -147 to $-181 \%$. Although the range of the $\delta \mathrm{D}$ values in the magmatic minerals is significantly larger than in the alteration phase, the mean values for both are similar (i.e. $-182 \pm 32 \%$ and
$-170 \pm 14 \%$, respectively). We note that the large spread in the $\delta \mathrm{D}$ values in the magmatic minerals (of $\sim-140 \%$ ) cannot be attributed to a statistical error in the measurements since this error is in the range of $30-40 \%$ for low hydrogen (water) content.

There may be two possible explanations for these hydrogen isotopic systematics, both of which require that the $\delta \mathrm{D}$ value recorded in the alteration phase reflects that of the fluid from which it was formed. The spread in the $\delta \mathrm{D}$ values in the magmatic minerals could result from heterogeneous isotopic fractionation between these minerals and the fluid that deposited the alteration phase. Isotopic fractionation between fluids and silicates is generally too small to account for the observed variation of $\delta \mathrm{D}$ in the magmatic minerals, but redox reactions (accompanied by liberation of $\mathrm{H}_{2}$ ) of the fluid with the silicates 


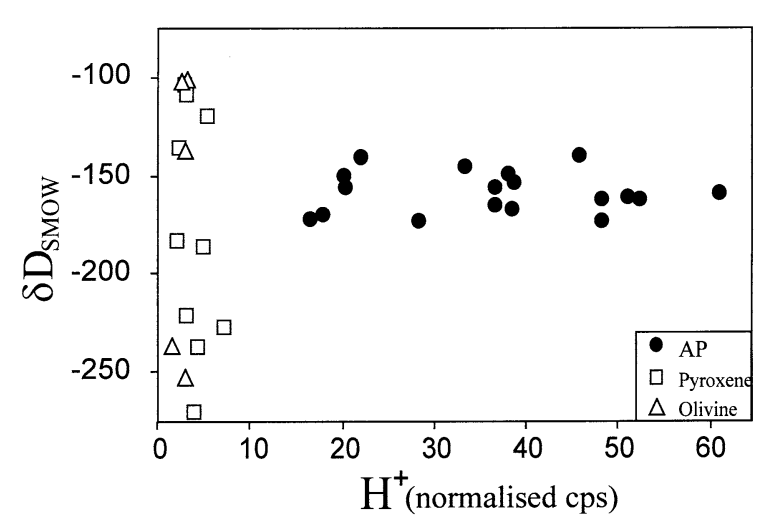

Fig. 4. Hydrogen isotope data obtained by ion microprobe on the magmatic minerals (olivines and augites) and on the alteration product of NWA 817. The data are expressed in $\delta \mathrm{D}$ units.

under reducing conditions can lead to much higher fractionation (up to a few $100 \%$ ) [22] and may leave a heterogeneous isotopic signature in the magmatic minerals that previously had uniform $\delta \mathrm{D}$ values. Another possibility is that the $\delta \mathrm{D}$ for the two types of minerals were both set at the time of deposition of the alteration phase. Subsequently, interaction and incomplete equilibration with other fluids (on Mars and/or possibly on Earth) with somewhat different $\delta \mathrm{D}$ compositions could result in a larger spread in the $\delta \mathrm{D}$ values in the magmatic minerals. This is because these (nominally anhydrous) minerals have a significantly lower hydrogen content than the alteration phase and are, therefore, more susceptible to having their hydrogen isotopic systematics altered by fluids with different $\delta \mathrm{D}$ compositions.

How reasonable is it to assume that the mean $\delta \mathrm{D}$ value of $-170 \pm 14 \%$ o recorded in the alteration phase indeed reflects the hydrogen isotopic composition of fluid from which it was formed on Mars and not that of terrestrial water? Even if the textural arguments rule out the formation of the alteration phase on Earth we discuss in detail the potential effects of the interaction with terrestrial water on the pristine $\mathrm{D} / \mathrm{H}$ ratio of the meteorite, even if the textural arguments rule out the formation of the alteration phase on Earth.

First of all let us assume that the alteration phase formed on Earth due to the circulation of terrestrial water in the meteorite. $\delta \mathrm{D}$ values of rainwater and groundwater in Northwest Africa have been found to have minimum values down to only $\sim-80 \%$ in very exceptional cases and locations [23,24]. Let us use this value as a limiting one. Sheppard and Gilg [25] have reviewed the water-clay $\mathrm{D} / \mathrm{H}$ fractionation. For smectites, having similar iron content as the alteration product of NWA 817, the low temperature D/H fractionation factor with water can reach values down to $-60 \%$. Therefore, the alteration phase, if formed on Earth, could reach $\delta \mathrm{D}$ values down to $-140 \%$ if it is precipitated from water with a $\delta \mathrm{D}=-80 \%$. This value is significantly higher than the one measured in the alteration phase. Moreover, the texture and setting of the alteration phase within magmatic minerals rule out the circulation of large amounts of water in the meteorite and thus the permanent connexion with an external water reservoir. Therefore, the progressive growth of the alteration phase from water within the meteorite will lead to an increase toward higher values of the $\mathrm{D} / \mathrm{H}$ ratio of both water and alteration phase. This phase in the $\mathrm{D} / \mathrm{H}$ ratio is not observed in the alteration phase, which in turn exhibits rather constant values.

Contamination by terrestrial $\mathrm{H}$ (adsorbed on mineral surfaces or resulting from water-mineral exchange) after the arrival on Earth must also be discussed. The few negative $\delta \mathrm{D}$ values previously reported in Martian meteorites have been explained in terms of contamination by terrestrial adsorbed water [26]. However, water adsorbed during sample preparation, estimated by monitoring the $\mathrm{H}_{2}^{+} / \mathrm{H}^{+}$ratio as described by Deloule et al. [21], was minimal in our analysis of magmatic minerals and alteration phase, confirming that the measured $\delta \mathrm{D}$ values are representative of hydrogen located in the bulk of the minerals. Nevertheless, it may still be argued that the hydrogen located in the bulk of the minerals in NWA 817 has exchanged with terrestrial water and that the negative $\delta \mathrm{D}$ values measured in this rock were produced during extensive circulation of water in this meteorite during its residence time in the Saharan desert. However, this scenario is unlikely and several lines of evidence argue against a sig- 
nificant alteration of the $\delta \mathrm{D}$ values in the alteration phase during terrestrial weathering of NWA 817. As noted earlier, textural and chemical evidence indicates very limited circulation of terrestrial fluids in NWA 817. Thus, although waterbearing clays in meteorites can exchange $\mathrm{H}$ with percolating water under desert conditions [27], it seems extremely difficult to obtain the most negative $\delta \mathrm{D}$ values observed in both the alteration phase and magmatic minerals of NWA 817 by this means. In fact, heated desert water percolating through the meteorite will be subjected to evaporation, with the consequence of a shift of its $\delta \mathrm{D}$ toward higher values [28]. Changes in $\delta \mathrm{D}$ toward lower values induced by Saharan alteration have been described in carbonaceous chondrites [29]. However, in this case the depletion in D was apparently related to the hydrolysis of organic matter. The absence of a significant organic component in NWA 817 and the fact that the $\delta \mathrm{D}$ measurements were conducted on individual, wellcharacterized phases rule out this possibility. Therefore, only the highest $\delta \mathrm{D}$ values observed in the magmatic minerals may be reasonably attributed to a Saharan alteration process. Consequently, it is highly unlikely that such alteration can produce the low $\delta \mathrm{D}$ values measured in the main water-bearing phase in NWA 817 (alteration phase) and it is reasonable to assume that the mean $\delta \mathrm{D}$ value in this phase $(-170 \pm 14 \%$ o represents the hydrogen isotopic composition of its parent fluid on Mars.

This $\delta \mathrm{D}$ value is significantly lower than those measured in other nakhlites and most other Martian meteorites (by either step heating experiments on bulk samples [26] or by ion microprobe analyses on individual H-rich minerals) [6,26]. $\delta \mathrm{D}$ values reported so far in Martian meteorites are mostly positive and range between +500 and $+4300 \%$ [6,26,30]. For the magmatic minerals, these elevated and variable values have been interpreted in terms of interaction to different degrees with Martian groundwater that had equilibrated with the highly fractionated D-enriched Martian atmosphere (with a present $\delta \mathrm{D}$ value of $\sim+4000 \%$ ) [31]. Clearly, the negative $\delta \mathrm{D}$ values in the alteration phase and magmatic minerals of NWA 17 cannot be similarly interpreted.

\section{Conclusion}

The formation of the alteration phase, a ferromagnesian silicate of the smectite family, in NWA 817 indicates a post-magmatic alteration process occurring under low-temperature conditions (less than $500^{\circ} \mathrm{C}$ ) [32]. Similar processes are known on Earth. Smectite formation has been observed as a result of the interaction between basalts and other volcanic rocks with juvenile water (from the mantle) or seawater [32]. If the low mean $\delta \mathrm{D}$ value in the alteration phase is indeed pristine and unaffected by the residence of NWA 817 on Earth, then it represents a water reservoir on Mars with a $\delta \mathrm{D}$ value distinct from that of the present Martian atmosphere. We note that this low $\delta \mathrm{D}$ value is close to the mean value of carbonaceous chondrites [33] and may reflect a 'primitive' unfractionated water reservoir on Mars. The striking similarity of NWA 817 with the other three nakhlites strongly suggests that it also has a similar crystallization age (of $\sim 1.3 \mathrm{Ga}$ ) [1,34]. Thus, the time of formation of the alteration phase was most likely $<1.3 \mathrm{Ga}$. By this time, the Mars atmosphere was already highly fractionated in its hydrogen isotopic composition. For a water reservoir to remain unfractionated on Mars $<1.3$ $\mathrm{Ga}$ ago, it must be isolated from the Martian atmosphere and groundwater (which likely equilibrated with the atmosphere). Such a water reservoir is most likely to be in the Martian mantle. Several previous studies have suggested that Mars has not sustained global plate tectonics [35-37] and therefore its mantle could effectively remain isolated from crustal and atmospheric water reservoirs. Therefore, the alteration products in NWA 817 likely represent the first evidence of alteration of the Martian crust by a 'primitive' aqueous fluid (i.e. with an unfractionated hydrogen isotopic composition). A further implication of a low $\mathrm{D} / \mathrm{H}$ ratio for primitive water on Mars is that at a significant proportion of the Martian surface hydrogen (or water) must have been lost through time. Assuming a $\delta \mathrm{D}$ of $-170 \%$ for the primitive water and the current $\delta \mathrm{D}$ of the atmosphere of $+4200 \%$, the surface hydrogen (water) reservoir on Mars needs to be depleted by at least $\sim 84 \%$. 


\section{Acknowledgements}

This collaborative work has been initiated through the French Martian sample program from the CNES and the French program PNP from the INSU. All the authors are extremely indebted to Bruno Fectay and C. Bidaut who provided this extraordinary meteorite. M. Mezouard (ESRF Grenoble) kindly performed the diffraction experiments. B. Champagnon gave us access to the IR spectrometer. Access to the Washington University ion microprobe was courtesy of G. Crozaz. We are grateful to F. Robert, C. Lécuyer, M. Javoy, F. Albarède and G. Crozaz for helpful discussions during this work.[AC]

\section{Appendix. Samples and analytical techniques}

Three types of samples were used to characterize the post-magmatic alteration products of NWA 817: two centimeter-sized chips embedded in epoxy and polished on one side; one thin section, single crystals of olivine hand-picked from powders and presenting reddish alteration features. All these samples were first studied by optical microscopy in both transmitted and reflected light. Backscattered electron images were taken with a JEOL JSM6301-F scanning electron microscope equipped with an energy dispersive spectrometer. High-magnification images were recorded in the FEG-SEM mode in order to detect subtle structural and chemical details in the alteration products.

$\mathrm{X}$-ray diffraction measurements were performed on olivine single crystals at the European Synchrotron Radiation Facility (Grenoble, France). A monochromatic beam with a wavelength of $0.3738 \AA$ was used. The diffracted X-rays were recorded on a CCD camera. The sample was held in a silica capillary and rotated by $\pm 30^{\circ}$. The beam size was around $30 \mu \mathrm{m}$. TEM observations were carried out on flakes of the alteration product separated by hand-picking from crushed crystals of olivine. The flakes have been included in epoxy and thin slices were cut by ultra-microtomy.

Raman spectra were recorded with a T64000
Jobin-Yvon ${ }^{\circledR}$ spectrometer (located at the Institut de Physique du Globe de Paris) equipped with confocal optics and a nitrogen-cooled CCD detector. A microscope is used to focus the excitation laser beam $\left(514 \mathrm{~nm}\right.$ lines of a Spectra Physics ${ }^{\circledR}$ $\mathrm{Ar}^{+}$laser and $647 \mathrm{~nm}$ lines of a Coherent ${ }^{\circledR} \mathrm{Kr}$ laser) to a $2 \mu \mathrm{m}$ spot and to collect the Raman signal in the backscattered direction. Accumulations lasting from $30 \mathrm{~min}$ to $1 \mathrm{~h}$ have been made. The laser power at the sample was $2-50 \mathrm{~mW}$ to avoid deterioration of the sample. Infrared spectra were obtained with a Perkin-Elmer Spectrum GX spectrometer equipped with a microscope stage. Transmission spectra were recorded directly on the thin section on an area $30 \times 30 \mathrm{~mm}$ in size. Accumulation of 1000 scans gave good spectra.

Chemical compositions in major elements were obtained with a Cameca SX50 electron microprobe (located at the Université de Paris VI). Operating conditions for the microprobe analyses were $15 \mathrm{kV}$ accelerating voltage with a beam current of $12 \mathrm{nA}$. REEs were measured in situ with a modified Cameca IMS-3f ion microprobe at the University of Washington, St. Louis, MO, USA. The analytical methods are similar to those described by Zinner and Crozaz [16] and Lundberg et al. [15]. Secondary ions were sputtered from the sample surface using an $\mathrm{O}^{-}$primary beam of $5 \mathrm{nA}$, resulting in spot sizes about $20 \mu \mathrm{m}$ in diameter. Six large areas of the orange alteration product located in two olivine crystals were analyzed.

Hydrogen isotopic compositions were measured in situ on polished sections with the Cameca IMS 1270 ion microprobe located at the CRPGCNRS, Nancy. An $\mathrm{O}^{-}$primary beam of $2-5 \mathrm{nA}$ were accelerated at $13 \mathrm{kV}$ and focused on the sample to a beam of $30 \mu \mathrm{m}$ in diameter. The secondary beam mass resolution was set at 2000, with an energy window of $55 \mathrm{eV}$, without any energy offset. Secondary ions $\mathrm{H}^{+}, \mathrm{D}^{+}$and $\mathrm{H}_{2}^{+}$ were measured during $20 \mathrm{~min}$ each by ion counting and peak switching. Statistical precision ranging from $\pm 30 \%$ for samples with low water content to less than $10 \%$ for samples with high water content were attained. Amphibole and pyroxene standards were used to correct for the instrumental isotopic fractionation, calculated as a function of the Mg-number of the analyzed 
phases [21,38]. Results are given in $\delta \mathrm{D}_{\text {SMOW }}$ units $\left(\delta \mathrm{D}_{\text {sample }}=\left[(\mathrm{D} / \mathrm{H})_{\text {sample }} /(\mathrm{D} / \mathrm{H})_{\mathrm{SMOW}}-1\right] \times 1000\right)$ with a precision of $40-20 \%$, including the instrumental calibration uncertainty. Samples were carefully degassed by heating under high vacuum before introduction into the analytical chamber. The instrumental background was measured on international standards [39]. It is lower than 10 ppm of water with counting rates $10-100$ times lower than the lowest counting rate observed for the minerals of NWA 817 . The instrumental moisture displays a $\mathrm{D} / \mathrm{H}$ ratio in the range 50 $60 \times 10^{-6}$, corresponding to $\delta \mathrm{D}$ values of less than $-500 \%$. Instrumental contamination during the analysis of minerals containing very low amounts of hydrogen like olivine and pyroxene is ruled out since no correlation was observed between the $\mathrm{H}^{+}$counting rate and the $\mathrm{D} / \mathrm{H}$ ratio. During analysis of the hydrous alteration phase the vacuum remained below $10^{-8}$ Torr, indicating that the interstitial water has been correctly removed from the sample surface. Furthermore, interstitial water is not included in ion probe measurements but pumped out from the sample during measurement and only structural water of the alteration phase is analyzed.[AC]

\section{References}

[1] H.Y.J. McSween, What we learned about Mars from SNC meteorites, Meteoritics 29 (1994) 757-779.

[2] A.M. Reid, T.E. Bunch, The nakhlites part II: Where, when and how, Meteoritics 10 (1975) 317-324.

[3] J.L. Gooding, S.J. Wentworth, M.E. Zolensky, Aqueous alteration in the Nakhla meteorite, Meteoritics 26 (1991) 135-143.

[4] A.H. Treiman, R.A. Barrett, J. Godding, Preterrestrial alteration of the Lafayette (SNC) meteorite, Meteoritics 28 (1993) 86-97.

[5] J.C. Bridges, M.M. Grady, Evaporite mineral assemblages in the nakhlite (martian) meteorites, Earth Planet. Sci. Lett. 176 (2000) 267-279.

[6] L.L. Watson, I.D. Hutcheon, S. Epstein, E.M. Stolper, Water on Mars clues from deuterium/hydrogen and water contents of hydrous phases in SNC meteorites, Science 265 (1994) 86-90.

[7] V. Sautter, J.A. Barrat, A. Jambon, M. Javoy, J.P. Lorand, P. Gillet, J.L. Joron, M. Lesourd, A new martian meteorite from Marocco: the nakhlite North West Africa 817, Earth Planet. Sci. Lett. 195 (2002) 223-338.
[8] H. Leroux, Microstructural shock signatures of major minerals in meteorites, Eur. J. Mineral. 13 (2001) 253 272.

[9] B. Marty, K. Marti, Signatures of early differentiation of Mars, Earth Planet. Sci. Lett. (2002) in press.

[10] A. Jambon, J.A. Barrat, P. Gillet, C. Göpel, M. Javoy, J.L. Joron, V. Sautter, One more shergottite from North Western Africa, Meteorit. Planet. Sci. 36 (2001) A90.

[11] J.A. Barrat, P. Gillet, V. Sautter, A. Jambon, M. Javoy, C. Göpel, M. Lesourd, F. Keller, E. Petit, Petrology and geochemistry of the basaltic shergottite North West Africa 480, Meteorit. Planet. Sci. 37 (2002) 487-499.

[12] J.A. Barrat, J. Blichert-Toft, R.W. Nesbitt, F. Keller, Bulk chemistry of Saharan shergottite Dar al Gani 476, Meteorit. Planet. Sci. 34 (2001) 91-97.

[13] P. Gillet, Application of vibrational spectroscopy to geology, in: J.M. Chalmers, P.R. Griffiths (Eds.), Handbook of Vibrational Spectroscopy, Vol. 4, John Wiley and Sons, (2002) pp. 1-23.

[14] A.H. Treiman, D.J. Lindstrom, Trace element geochemistry of martian iddingsite in the Lafayette meteorite, J. Geophys. Res. 102 (1997) 9153-9163.

[15] L.L. Lundberg, G. Crozaz, G. McKay, E. Zinner, Rare earth element carriers in the Shergotty meteorite and implications for its chronology, Geochim. Cosmoschim. Acta 52 (1988) 2147-2163.

[16] E. Zinner, G. Crozaz, A method for the quantitative measurement of rare earth elements in the ion-microprobe, Intl. J. Mass Spectrom. Ion Proc. 69 (1986) 17-38.

[17] J.A. Barrat, P. Gillet, M. Lesourd, J. Blichert-Toft, G.R. Poupeau, The Tatahouine diogenite mineralogical and chemical effects of 63 years of terrestrial residence, Meteorit. Planet. Sci. 34 (1999) 91-97.

[18] G. Crozaz, M. Wadhwa, The terrestrial alteration of Saharan shergottites Dar al Gani 476 and 489: a case study of weathering in a hot desert, Geochim. Cosmoschim. Acta 65 (2001) 971-978.

[19] M. Wadhwa, J.A. Barrat, G. Crozaz, Petrogenesis of a new nakhlite from rare earth and trace elements distribution, Meteorit. Planet. Sci. 36 (2001) A216-A217.

[20] A. Michard, F. Albarède, G. Michard, J.F. Minster, J.L. Charlou, Rare-earth elements and uranium in high-temperature solutions from East Pacific Rise hydrothermal vent field $\left(13^{\circ} \mathrm{N}\right)$, Nature 303 (1983) 795-797.

[21] E. Deloule, C. France-Lanord, F. Albarède, D/H analysis of minerals by ion microprobe, in: H.P. Taylor, J.R. O’Neil, I.R. Kaplan (Eds.), Stable Isotope Geochemistry: a Tribute to Samuel Epstein, Vol. 3, Geochemical Society, Houston, TX, 1991, pp. 53-64.

[22] P. Richet, Y. Bottinga, M. Javoy, A review of hydrogen, carbon, nitrogen, oxygen and chlorine stable isotope fractionation among gaseous molecules, Annu. Rev. Earth Planet. Sci. 5 (1977) 65-110.

[23] J.R. Gat, A. Issar, Desert isotope hydrology: water sources of the Sinai desert, Geochim. Cosmochim. Acta 38 (1974) 1117-1131.

[24] R. Gonfiantini, T. Dincer, A.M. Derekoy, Environmental 
isotope hydrology in the Hodna region Algeria, in: Isotope Techniques in Groundwater Hydrology, IAEA, 1974, pp. 293-316.

[25] S.M.F. Sheppard, A. Gilg, Stable isotope geochemistry of clay minerals, Clay Miner. 31 (1996) 1-24.

[26] L.A. Leshin, S. Epstein, E.M. Stolper, Hydrogen isotope geochemistry of the SNC meteorites, Geochim. Cosmoschim. Acta 60 (1996) 2636-2650.

[27] S.M. Savin, S. Epstein, The oxygen and hydrogen isotope geochemistry of clay minerals, Geochim. Cosmoschim. Acta 34 (1970) 25-42.

[28] J.R. Gat, C. Browser, The heavy isotope enrichment of water in coupled evaporative systems, in: H.P. Taylor, J.R. O'Neil, I.R. Kaplan (Eds.), Stable Isotope Geochemistry: a Tribute to Samuel Epstein, Vol. 3, Geochemical Society, Houston, TX, 1991, pp. 159-168.

[29] R.D. Ash, T. Pillinger, Carbon, nitrogen and hydrogen in saharan chondrites: the importance of weathering, Meteoritics 30 (1995) 85-92.

[30] L.A. Leshin, Insigths into martian water reservoirs from analyses of martian meteorite QUE94201, Geophys. Res. Lett. 27 (2000) 2017-2020.

[31] G.L. Bjoraker, M.J. Mumma, H.P. Larson, Isotope abundance ratios for hydrogen and oxygen in the martian atmosphere, Bull. Am. Astron. Soc. 21 (1989) 991-996.

[32] N. Güven, Smectites, in: S.W. Bayley (Ed.), Hydrous Phyllosilicates, Reviews in Mineralogy 19, Mineralogical
Society of America, Washington, DC, 1988, pp. $497-$ 522.

[33] E. Deloule, F. Robert, J.C. Doukhan, Interstellar hydrox$\mathrm{yl}$ in meteoritic chondrules: implications for the origin of water in the inner solar system, Geochim. Cosmochim. Acta 62 (1998) 3367-3378.

[34] B. Marti, K. Marty, K.V. Mathew, Meteorit. Planet. Sci. 36 (2001) A122.

[35] C.L.J. Harper, L.E. Nyquist, B.M. Bansal, H. Wiesmann, C.Y. Shih, Rapid accretion and early differentiation of Mars indicated by ${ }^{142} \mathrm{Nd} /{ }^{144} \mathrm{Nd}$ in SNC meteorites, Science 267 (1995) 213-216.

[36] D.C. Lee, A.N. Halliday, Core formation on Mars and differenciated asteroids, Nature 388 (1997) 854-857.

[37] M. Wadhwa, Redox state of Mars' upper mantle and crust from Eu anomalies in shergottite pyroxenes, Science 291 (2001) 1527-1530.

[38] C. Engrand, E. Deloule, F. Robert, M. Maurette, G. Kurat, Extraterrestrial water in micrometeorites and cosmic spherules from Antarctica: an ion microprobe study, Meteorit. Planet. Sci. 34 (1999) 773-786.

[39] D.R. Bell, P.D. Ihringer, G.R. Rossman, Quantitative analysis of trace $\mathrm{OH}$ in garnet and pyroxenes, Am. Mineral. 80 (1995) 465-474.

[40] N.M. Evensen, P.J. Hamilton, R.K. O'Nions, Rare earth abundances in chondritic meteorites, Geochim. Cosmochim. Acta 42 (1978) 1199-1212. 